\title{
Effects of bioturbation on solutes and solids in marine sediments
}

\author{
Peter Berg ${ }^{1, *}$, Søren Rysgaard ${ }^{2}$, Peter Funch ${ }^{3}$, Mikael K. Sejr ${ }^{4}$ \\ ${ }^{1}$ Department of Environmental Sciences, University of Virginia, Charlottesville, Virginia 22903, USA \\ ${ }^{2}$ National Environmental Research Institute, Department of Lake and Estuarine Ecology, Vejlsøvej 25, \\ 8600 Silkeborg, Denmark \\ ${ }^{3}$ Institute for Biological Sciences, Department of Zoology University of Århus, Universitetsparken, 800 Århus C, Denmark \\ ${ }^{4}$ Institute for Biological Sciences, Department of Marine Ecology, University of Århus, Findlandsgade 14, 8200 Århus N, \\ Denmark
}

\begin{abstract}
Bioturbation, the mixing of solutes and solids in sediments caused by movements of fauna, was studied through tracer experiments and numerical modeling. The generally accepted mathematical formulation of transport by bioturbation as a diffusive process was applied and values of the biodiffusivity $\left(D_{\mathrm{B}}\right)$ were estimated for both dissolved and solid constituencies in the same sediment. Two independent estimates were found for each constituency. For solutes, $D_{\mathrm{B}}$ was determined from incubated sediment cores after addition of bromide to the overlying water and subsequent modeling of the bromide depth-distributions in the sediment. $D_{\mathrm{B}}$ for solutes was also estimated by comparing interpretations of measured concentration-depth profiles and fluxes of $\mathrm{O}_{2}$. For solids, $D_{\mathrm{B}}$ was estimated from modeling the depth-distributions of glass beads, which were added to the sediment surface in the same cores as used for the bromide tracer experiments. In addition, $D_{\mathrm{B}}$, also for solids, was determined by interpretations of 2 measured ${ }^{210} \mathrm{~Pb}$ depth profiles. We validated our findings through sensitivity analyses and comparisons to other studies. As part of this process we tested if irrigation, the pumping activity of tube-dwelling animals, could influence our results. It is commonly assumed that the same $D_{\mathrm{B}}$ value applies to both the bioturbation of solutes and solids. Our analyses, however, show clearly that the effects of bioturbation on solutes are many fold stronger than on solids, as reflected in the estimated $D_{\mathrm{B}}$ value of $4.6 \pm 1.0 \times 10^{-6}(1 \mathrm{SE}) \mathrm{cm}^{2} \mathrm{~s}^{-1}$ for solutes and a value that is 15 to 20 times smaller for solids. The results also show that the transport of solutes by bioturbation is equally as important as molecular diffusion in the upper sediment layers (few $\mathrm{cm}$ ). Since the density and species composition of fauna in the studied sediment were comparable to those at many other near-shore marine sites, we believe that our results are general for many sediments. We suggest that the recognized mathematical formulation of bioturbation as a diffusive process be extended to include 2 different biodiffusivities, one for solutes and one for solids.
\end{abstract}

KEY WORDS: Bioturbation $\cdot$ Biodiffusivity $\cdot$ Pore water $\cdot$ Sediments $\cdot$ Meio- and macrofauna

Resale or republication not permitted without written consent of the publisher

\section{INTRODUCTION}

Transport rates of chemicals are often used in biogeochemical studies of sediments to produce estimates of variables such as fluxes over the sediment-water interface. This is obviously only possible if the active transport processes are known and if they can be

*E-mail: pb8n@virginia.edu quantified. Bioturbation, the diffusive-like transport of solutes and solids in sediments caused by movements of fauna, is often a significant transport process (Aller 1982, Aller \& Yingst 1985, Aller \& Aller 1992, Forster et al. 1995). It is commonly described mathematically as a diffusive process where the strength is expressed in the value of the biodiffusivity $\left(D_{\mathrm{B}}\right)$. The importance of bioturbation as a significant contributor to the transport in sediments is also reflected in the number of studies that have focused on finding $D_{\mathrm{B}}$ values for var- 
ious sediments (Middelburg et al. 1997). Despite the large variability in $D_{\mathrm{B}}$ values, studies have successfully correlated $D_{\mathrm{B}}$ to key parameters such as sedimentation rate (Boudreau 1994, 1997) or water depth (Middelburg et al. 1997).

The generally accepted 1-dimensional and nonsteady-state mass conservation equation that accounts for the transport of solutes by molecular diffusion and bioturbation (Dhakar \& Burdige 1996, Soetaert et al. 1996, Van Cappellen \& Wang 1996, Boudreau 1997) is as follows:

$$
\varphi \frac{\partial C}{\partial t}=\frac{\partial}{\partial x}\left(\varphi\left(D_{\mathrm{s}}+D_{\mathrm{B}}\right) \frac{\partial C}{\partial x}\right)
$$

where $\varphi$ is porosity, $C$ pore water concentration, $t$ time, $x$ depth, $D_{\mathrm{s}}$ molecular diffusivity corrected for tortuosity, and $D_{\mathrm{B}}$ biodiffusivity. The equivalent equation for solids yields:

$$
(1-\varphi) \frac{\partial B}{\partial t}=\frac{\partial}{\partial x}\left((1-\varphi) D_{\mathrm{B}} \frac{\partial B}{\partial x}\right)
$$

where $B$ is the amount of mass of the species per unit volume of solid sediment (Berner 1980, Dhakar \& Burdige 1996, Soetaert et al. 1996, Van Cappellen \& Wang 1996, Boudreau 1997). In both equations, $\varphi$ is assumed to be constant with time, and advective transport processes are neglected. For further details about these equations see, for example, Boudreau (1997).

Unlike molecular diffusion, bioturbation affects both solutes and solids, and the strength or intensity of bioturbation is commonly assumed to be the same for both (Berner 1980, Dhakar \& Burdige 1996, Soetaert et al. 1996, Van Cappellen \& Wang 1996, Boudreau 1997). However, a comparison of recent studies where $D_{\mathrm{B}}$ has been estimated from experiments either with solid tracers (e.g., ${ }^{210} \mathrm{~Pb}$ ) or dissolved tracers (e.g., $\mathrm{Br}^{-}$or $\mathrm{Cl}^{-}$) indicates that this may not always be true. Middelburg et al. (1997) compiled a large selection ( $\mathrm{n}=132$ ) of ${ }^{210} \mathrm{~Pb}$ tracer measurements and found a mean $D_{\mathrm{B}}$ value for shallow waters $(<100 \mathrm{~m})$ between $3 \times 10^{-7}$ and $6 \times$ $10^{-7} \mathrm{~cm}^{2} \mathrm{~s}^{-1}$. In another study, also based on ${ }^{210} \mathrm{~Pb}$ measurements, Mulsow et al. (1998) found $D_{\mathrm{B}}$ values ranging from $3 \times 10^{-9}$ to $4 \times 10^{-7} \mathrm{~cm}^{2} \mathrm{~s}^{-1}$ (water depth $\sim 230$ to $830 \mathrm{~m}, \mathrm{n}=14$ ). Other studies involving dissolved tracers have shown that fauna can enhance the transport in sediments, with resulting rates that are several times higher than what can be accounted for by molecular diffusion alone (Aller \& Aller 1992, Forster et al. 1995, Glud \& Fenchel 1999, Rysgaard et al. 2000). This enhanced transport of solutes is equivalent to $D_{\mathrm{B}}$ values on the order of $10^{-6}$ to $10^{-4} \mathrm{~cm}^{2} \mathrm{~s}^{-1}$. Although the effects of irrigation, the exchange of pore water and bottom water caused by pumping activity of tubedwelling animals, might explain some of the largest differences between such estimated $D_{\mathrm{B}}$ values for solids and for solutes, we believe the differences are real and reflect that fauna, primarily meiofauna, can move pore water at higher rates than solid components.

The generally accepted mathematical formulation of bioturbation as a transport process is based on the assumptions that the movements of fauna are random and that the resulting bulk mixing of sediment (solutes and solids) happens on a size scale that is small relative to the scale adapted when using the formulation. These are the essential assumptions that allow the complex mixing processes to be described as a simple diffusive process. The validity of the assumptions is shown to be correct by the successful use of the formulation in numerous studies. Although water is not a particularly easy-flowing liquid at a small size scale $(<\mathrm{mm})$, it still can be moved with less effort than most solid fractions of a sediment. For that reason, there is the potential that faunal activity can move pore water at a higher rate than solid components. Such an interstitial convective transport of pore water should not be confused with the non-local transport by irrigation as defined above. Furthermore, the directions of these convective transport contributions are believed to be random and to happen on a small size scale similar to the bulk mixing of sediment. This allows us to describe the convective pore water transport as a diffusive process. The movements of meio- and macrofauna in canals or tubes randomly orientated within the sediment may also play an important role in this enhanced small-scale pore water transport. The effects of the movements of fauna, and for some species also their feeding behaviors, on the transport in sediments are still not fully understood, and surprising results are frequently published. For example, Aller \& Aller (1992) showed that the meiofauna in marine muds can enhance the diffusive-like solute transport by a factor of approximately 2 relative to molecular diffusion. Glud et al. (1995) found that a smaller, but still significant, enhancement of the solute transport of $20 \%$ in surface sediments was attributed to meiofauna. Some studies also have focused on smaller organisms and their effects on the pore water transport in sediments. Östlund et al. (1989) studied sulfate-reducing bacteria and showed that the effective diffusion coefficients were $20 \%$ larger in microbially active sediments than in sterile ones. A more extreme example is given by Fenchel \& Glud (1998), who demonstrated that sulfateoxidizing bacteria in a limited micro-environment can stimulate solute transport by a factor of 40 relative to molecular diffusion.

In this study, we have investigated the diffusive-like transport of both solutes and solids in the same sediment in a series of tracer experiments involving both dissolved and solid tracers which were added or natu- 
rally present in the sediment. Through inverse numerical modeling, independent estimates of $D_{\mathrm{B}}$ were subsequently produced for both solutes and the solids. In order to show that the fauna responsible for the transport in our sediment is comparable to many other sediments, we also describe the meio- and macrofauna populations present at our study site. The enhanced pore water transport relative to the transport of solids could be included in a mathematical formulation by defining a new diffusivity for solutes to be added to $D_{\mathrm{s}}$ and $D_{\mathrm{B}}$ in Eq. (1). However, since this enhanced pore water transport is caused by faunal activity and is believed to be happening on a size scale comparable to that of bulk sediment mixing so that it can be described as a diffusive process, we have chosen to include the additional contribution in the existing formulation as bioturbation by defining 2 biodiffusivities, one for solids and a larger one for solutes.

\section{METHODS}

Study site and sampling. The experiment was conducted with sediment from a site located at $36 \mathrm{~m}$ water depth in Young Sound in Northeast Greenland $\left(74^{\circ} 18.58^{\prime} \mathrm{N}, 20^{\circ} 15.04^{\prime} \mathrm{W}\right)$. For further details of the sampling site see Rysgaard et al. (1998).

Sediment was collected in $30 \mathrm{~cm}$ long Plexiglas tubes that sampled $22 \mathrm{~cm}^{2}$ of the seafloor. Only undisturbed sediment cores with clear overlying water and without large epifauna were kept for further processing. The sediment cores were immediately placed in an insulated box and brought back to the laboratory within 1 to $2 \mathrm{~h}$. In the laboratory, a small Tefloncoated magnet $(0.5 \times 3 \mathrm{~cm})$ was placed $5 \mathrm{~cm}$ above the sediment surface and the cores were submerged in a tank with in situ bottom water and kept in the dark at the in situ temperature of $-1^{\circ} \mathrm{C}$ and at air saturation. The water in the cores was mixed by rotating the Teflon-coated magnets at $60 \mathrm{rpm}$, and all cores were pre-incubated for $24 \mathrm{~h}$ before further processing to minimize effects of any disturbances of the sediment during collection.

Sediment characteristics. Porosity was determined from the sediment density and water content measured as weight loss after drying at $105^{\circ} \mathrm{C}$ for $24 \mathrm{~h}$. This was done on sediment samples taken at $1 \mathrm{~cm}$ depth intervals from 4 cores. In addition, sediment from each depth interval was partitioned into various size fractions after the samples were dispersed in distilled water and briefly sonicated to disaggregate any clumps. This suspension was passed through 125, 63, and $36 \mu \mathrm{m}$ sieves in order to collect the following particle size fractions of the sediment: $>125,63-125,36-$ 63 , and $<36 \mu \mathrm{m}$.
Tracer experiment with $\mathrm{Br}^{-}$and glass beads. $\mathrm{Br}^{-}$was added to the incubation tank and mixed homogeneously with the water in each sediment core to achieve a concentration of approximately $20 \mathrm{mM}$. The large water volume in the incubation tank insured a constant $\mathrm{Br}^{-}$concentration in the water overlying the sediment throughout the tracer experiment. Immediately after the addition of $\mathrm{Br}^{-}, 1 \mathrm{ml}$ of spherical glass beads ( $10^{7}$ beads) with a diameter of 30 to $70 \mu \mathrm{m}$ representing the average sediment grain size distribution (see later) was dispersed evenly on the sediment surface in each core. Prior to the tracer experiment the beads were soaked in in situ bottom water for $1 \mathrm{wk}$ to obtain a biofilm on the surface.

At different times $(10,26,48,93,148,196$, and $240 \mathrm{~h})$ after adding the 2 tracers a core was removed from the tank and immediately sectioned into sixteen 3-10 mm slices. Pore water was extracted from each slice through Watmann GF/F filters using a pneumatic squeezer (modified after Reeburgh 1967) and a pressure of 3 to 5 bar. The pore water samples as well as the solid sediment samples left in the pneumatic squeezer were immediately frozen $\left(-18^{\circ} \mathrm{C}\right)$ for later determination of $\mathrm{Br}^{-}$and glass bead concentrations. One core (time $48 \mathrm{~h}$ ) was discarded because a rock fragment was found $2 \mathrm{~cm}$ below the sediment-water interface when sliced.

The $\mathrm{Br}^{-}$concentrations were determined on an anion chromatograph equipped with an autosampler (Waters ${ }^{\mathrm{TM}}, 712$ WISP) and a Waters type A column. Water samples taken prior to the tracer additions provided the background $\mathrm{Br}^{-}$concentration. The precision of the $\mathrm{Br}^{-}$determination was $<0.1 \mathrm{mM}$.

The solid sediment samples were dispersed in distilled water, briefly sonicated to disaggregate any clumps, and then dried at $105^{\circ} \mathrm{C}$ for $24 \mathrm{~h}$. Each sample was weighed and the number of glass beads were counted in triplicate subsamples $(\sim 0.5 \%$ of total weight) under an inverted microscope (100×: Olympus inverted microscope, Melville, NY). Standard errors of the subsample counts were $<6 \%(n=3)$.

Concentration profiles and fluxes of $\mathrm{O}_{2}$. Six vertical $\mathrm{O}_{2}$ concentration profiles were measured with a Clarktype $\mathrm{O}_{2}$ microelectrode (Revsbech 1989) at $500 \mu \mathrm{m}$ depth intervals in 3 sediment cores. Measurements were performed in the dark at the in situ temperature of $-1^{\circ} \mathrm{C}$ and with an overlying water column of $2 \mathrm{~cm}$ aerated by a flow of atmospheric air to ensure sufficient stirring while measuring.

The exchange of $\mathrm{O}_{2}$ between the water column and sediment was measured on 6 intact cores. The sediment cores were adjusted to give a height of the sediment and water column of $\sim 10$ and $\sim 20 \mathrm{~cm}$, respectively. The sediment cores were incubated in the dark at the in situ temperature, and the water column was 
continuously stirred during the flux measurements as in the pre-incubation period. At the start of the measurements a floating gas-tight lid $\left(21.2 \mathrm{~cm}^{2}\right)$ was placed on top of the water column in each core. To minimize gas exchange between water and atmosphere, the lids were carefully removed only when water samples were collected. During incubation ( 24 to $48 \mathrm{~h}$ ) changes in $\mathrm{O}_{2}$ concentration in the water column never exceeded $20 \%$ of the initial $\mathrm{O}_{2}$ concentration. Water samples were collected 4 to 5 times within the incubation period in order to verify a linear concentration change over time. The water samples were analyzed for the concentration of $\mathrm{O}_{2}$ by Winkler titration within $12 \mathrm{~h}$ of sampling.

Estimation of $D_{\mathrm{B}}$ from tracer experiment with $\mathrm{Br}^{-}$and glass beads. Eq. (1) was solved numerically using a control volume approach as described by Berg et al. (1998). In short, the sediment column was divided into $N$ horizontal layers, so-called control volumes, each with a grid point located in the center. It should be noted that a much higher resolution (large number of control volumes) was used in the numerical solution than when slicing the cores. The numerical solution allowed us to calculate a depth profile of $C$ based on known (or guessed) values of $\varphi, D_{\mathrm{s}}, D_{\mathrm{B}}$ and the appropriate boundary conditions for $C$. A depth-dependent fit to the measured porosities was used to calculate a value of $\varphi$ for each control volume, and values of $D_{\mathrm{s}}$ were calculated from $\varphi$ and the diffusivity in water $(D)$ according to Iversen \& Jørgensen (1993) (see details in 'Results'). At each time when a sediment core was sliced, depth profiles of $\mathrm{Br}^{-}$were calculated repeatedly for different 'guessed' values of $D_{\mathrm{B}}$. Through this process the value of $D_{\mathrm{B}}$ was successively adjusted so that the squared deviation between the measured and the calculated profile of $\mathrm{Br}^{-}$decreased. This deviation was defined as:

$$
\mathrm{SSE}_{\mathrm{Br}}=\sum_{i=1}^{M}\left(\mathrm{Br}_{m i}^{-}-\mathrm{Br}_{i}^{-}\right)^{2}
$$

where $M$ is the total number of measured concentrations per core, $\mathrm{Br}_{m i}^{-}$is the measured concentration, $\mathrm{Br}_{i}^{-}$ is the corresponding calculated concentration interpolated to the same depth as $\mathrm{Br}_{m i}^{-}$. This repetitive process of calculating profiles of $\mathrm{Br}^{-}$and adjusting $D_{\mathrm{B}}$ was continued until $\mathrm{SSE}_{\mathrm{Br}}$ reached a minimum value. For further details on how this minimization process was performed automatically, see Berg et al. (1998).

With 1 exception, a value of $D_{\mathrm{B}}$ was estimated for each glass bead profile in the same way. Since the glass beads were only found in the top layer of the sediment (see later), we averaged the calculated concentration of glass beads over the same depth intervals as used when slicing the cores before the squared deviation was determined. With this difference, the squared deviation was defined as:

$$
\mathrm{SSE}_{\mathrm{s}}=\sum_{i=1}^{M}\left(B_{m i}-\tilde{B}_{i}\right)^{2}
$$

where $M$ is the total number of slices of sediment per core, $B_{m i}$ is the number of glass beads counted per unit mass of solid sediment, and $\tilde{B}_{i}$ is the calculated mean number of glass beads per unit mass of solid sediment in the depth interval defined when slicing the cores.

Estimation of $D_{\mathrm{B}}$ from concentration profiles and fluxes of $\mathbf{O}_{2}$. $D_{\mathrm{B}}$ was also estimated in the top of the sediment by comparing the mean flux calculated from the measured $\mathrm{O}_{2}$ profiles with the $\mathrm{O}_{2}$ flux measured in the cores. Each of the 6 measured $\mathrm{O}_{2}$ profiles was used as input to the profile interpretation procedure of Berg et al. (1998). This procedure first determined an appropriate fit to the measured $\mathrm{O}_{2}$ profile based on F-statistics, and from that the $\mathrm{O}_{2}$ consumption rate as a function of depth and the flux over the sediment-water interface. Although the transport by molecular diffusion and bioturbation both can be included in the interpretation procedure, only molecular diffusion was taken into account. This means that the flux over the sediment-water interface $\left(F_{\mathrm{cal}}\right)$ as it was calculated in the profile interpretations can be expressed as $F_{\text {cal }}=-\varphi D_{\mathrm{s}}(\mathrm{d} C / \mathrm{d} x)_{X=0}$. If bioturbation was the only significant transport in addition to molecular diffusion (see 'Discussion') and if bioturbation had been included in the interpretations, a flux equal to the measured flux $\left(F_{\text {meas }}\right)$ should have been calculated. This flux can be expressed as $F_{\text {meas }}=$ $-\varphi\left(D_{\mathrm{s}}+D_{\mathrm{B}}\right)(\mathrm{d} C / \mathrm{d} x)_{X=0}$. Since the same approximations of $(\mathrm{d} C / \mathrm{d} x)_{X=0}$ would have been estimated in these hypothetic interpretations including bioturbation as in the interpretations where only molecular diffusion was taken into account, the following expression for $D_{\mathrm{B}}$ can be derived from the formulated fluxes $F_{\text {cal }}$ and $F_{\text {meas }}$ :

$$
D_{\mathrm{B}}=D_{\mathrm{s}}\left(\frac{F_{\text {meas }}}{F_{\text {cal }}}-1\right)
$$

$D_{\mathrm{B}}$ was calculated from Eq. (5), in which $D_{\mathrm{s}}$ was estimated according to Iversen \& Jørgensen (1993) (see 'Results'). It should be noted, that the same $D_{\mathrm{B}}$ also could be determined in a trial-and-error process where bioturbation was included in the 6 profile interpretations and were repeated and $D_{\mathrm{B}}$ adjusted until the calculated flux was equal to the measured flux.

Estimation of $D_{\mathrm{B}}$ from ${ }^{210} \mathrm{~Pb}$ profiles. Finally, $D_{\mathrm{B}}$ was estimated for the surficial sediment layers from 2 profiles of unsupported ${ }^{210} \mathrm{~Pb}$ reported by Rysgaard et al. $(1996,1998)$ for the same sediment as used in this study. Burial effects were neglected in these profile interpretations, assuming that the shape of the ${ }^{210} \mathrm{~Pb}$ profiles in the upper sediment layers was primarily the result of bioturbation (see discussion later). Under this condition, the 1-dimensional and steady-state mass conservation equation for ${ }^{210} \mathrm{~Pb}$ is: 


$$
\frac{\partial}{\partial x}\left((1-\varphi) D_{\mathrm{B}} \frac{\partial B}{\partial x}\right)-(1-\varphi) \lambda B=0
$$

where $B$ is the radioactivity of ${ }^{210} \mathrm{~Pb}$ and $\lambda$ the decay constant of ${ }^{210} \mathrm{~Pb}$ (Berner 1980, Boudreau 1997, Mulsow et al. 1998). $D_{\mathrm{B}}$ was estimated in a minimization process equivalent to the one applied for the $\mathrm{Br}^{-}$profiles. As part of this process, Eq. (6) was solved numerically using the same control volume approach as used for Eqs (1) \& (2).

Identification and quantification of meiofauna. In order to compare the studied sediment with respect to the fauna responsible for the bioturbation to other sediments, the meiofauna population was identified and quantified. Data for larger animals were taken from Sejr et al. (2000), who described the macrofauna on our site.

One of the collected sediment cores was fixed with $5 \%$ formalin buffered with borax and stored for later analysis of the meiofauna. The stain Rose Bengal was added to a subsample of the upper $5 \mathrm{~cm}$ of the sediment in order to distinguish live foraminifers from those that were dead when the core was collected (Wollenburg \& Mackensen 1998). The subsample was sieved wet using 1000, 125, 50, and $30 \mu \mathrm{m}$ sieves. The sediment retained in the $1000 \mu \mathrm{m}$ sieve was disregarded, while the fractions left in the other sieves were mixed with distilled water and examined using a Zeiss stereomicroscope at 40× magnification. Voucher specimens were collected and identified using a phase contrast or differential interference contrast microscope.

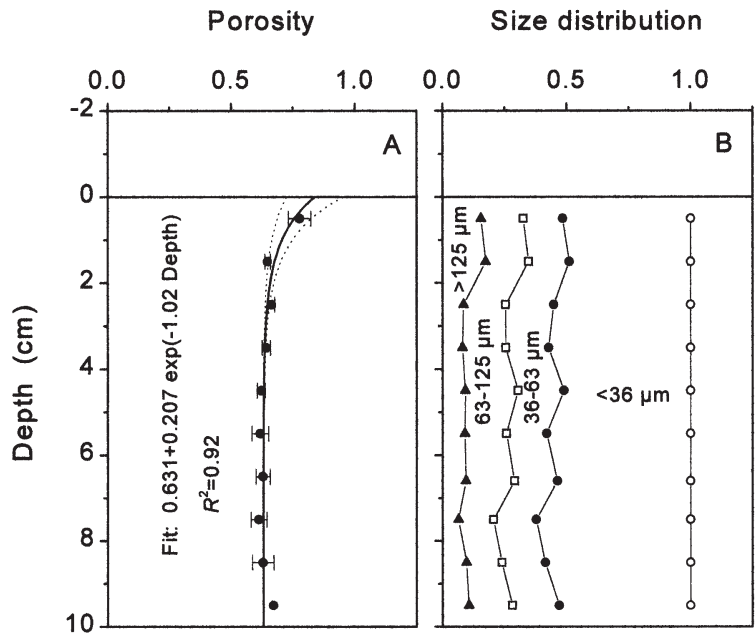

Fig. 1. (A) Measured porosity (dots) in the sediment and the fit to the porosity (line) used in all estimates of $D_{\mathrm{B}}$ (error bars represent $\pm 1 \mathrm{SE}, \mathrm{n}=4$ ). The 2 dotted lines represent the diffusivities used in a sensitivity analysis of the estimated $D_{\mathrm{B}}$ values. (B) Normalized particle size distribution of the sediment (the difference between the curves represent a size fraction), which was matched by the size distribution of the glass beads in the tracer experiment
Permanent whole-mounts were produced by adding droplets of glycerol of increasing concentrations to the fixative containing the meiofauna, letting the water evaporate, and finally sealing the whole-mounts with Glyceel ${ }^{\circledR}$. To estimate population sizes, additional distilled water was added to the sediment fractions retained in the 125, 50 and $30 \mu \mathrm{m}$ sieves to give total volumes of $100 \mathrm{ml}$. The mixtures were stirred to suspend all particles, 3 subsamples of $200 \mu \mathrm{l}$ were taken from each mixture, and the meiofauna were identified and counted using a differential interference contrast microscopy. Based on the average numbers of meiofauna in these subsamples and also on the number of meiofauna preserved in the whole-mounts, the total number of meiofauna was estimated for the upper $5 \mathrm{~cm}$ of the sediment.

\section{RESULTS}

\section{Sediment characteristics}

The porosity (Fig. 1A) decreased with depth from 0.78 in the top $1 \mathrm{~cm}$ of the sediment to an almost constant value of 0.63 at approximately $4 \mathrm{~cm}$. The porosity profile was fitted with a exponential decay function, which gave a fit of $0.631+0.207 \exp (-1.02 x)\left(\mathrm{R}^{2}=\right.$ $0.92)$, where $x$ is given in $\mathrm{cm}$. The particle size distribution (Fig. 1B) in the sediment was relatively constant with depth, with clay $(<36 \mu \mathrm{m})$ being the most dominant fraction $(\sim 55 \%)$. Silt $(36-63 \mu \mathrm{m})$ and very fine sand (63-125 $\mu \mathrm{m})$ each contributed about $17 \%$, and approximately $10 \%$ was coarser particles (>125 $\mu \mathrm{m})$.

\section{$D_{\mathrm{B}}$ estimated from tracer experiment with $\mathrm{Br}^{-}$ and glass beads}

The 6 measured profiles of $\mathrm{Br}^{-}$and glass beads used to estimate $D_{\mathrm{B}}$ values are shown in Fig. 2. The depthdependent values of $\varphi$ required in the numerical solutions of Eqs (1) \& (2) were determined from the porosity fit (Fig. 1A). The molecular diffusivity for $\mathrm{Br}^{-}$in water $(D)$ was calculated to be $9.43 \times 10^{-6} \mathrm{~cm}^{2} \mathrm{~s}^{-1}$ from the measured water temperature of $-1^{\circ} \mathrm{C}$ during the tracer experiment and the temperature correlation given by Boudreau (1997). The sediment diffusivity $\left(D_{\mathrm{s}}\right)$ as a function of depth was calculated as $D_{\mathrm{s}}=D /[1+$ $3(1-\varphi)]$ according to Iversen \& Jørgensen (1993). The average measured water column $\mathrm{Br}^{-}$concentration of $21.3 \pm 0.1(1 \mathrm{SE}) \mathrm{mM}(\mathrm{n}=6)$ was used as the top boundary condition, which was imposed at a height over the sediment-water interface equal to the thickness of the diffusive boundary layer (DBL). The large water volume in the incubation tank to which the $\mathrm{Br}^{-}$was added 

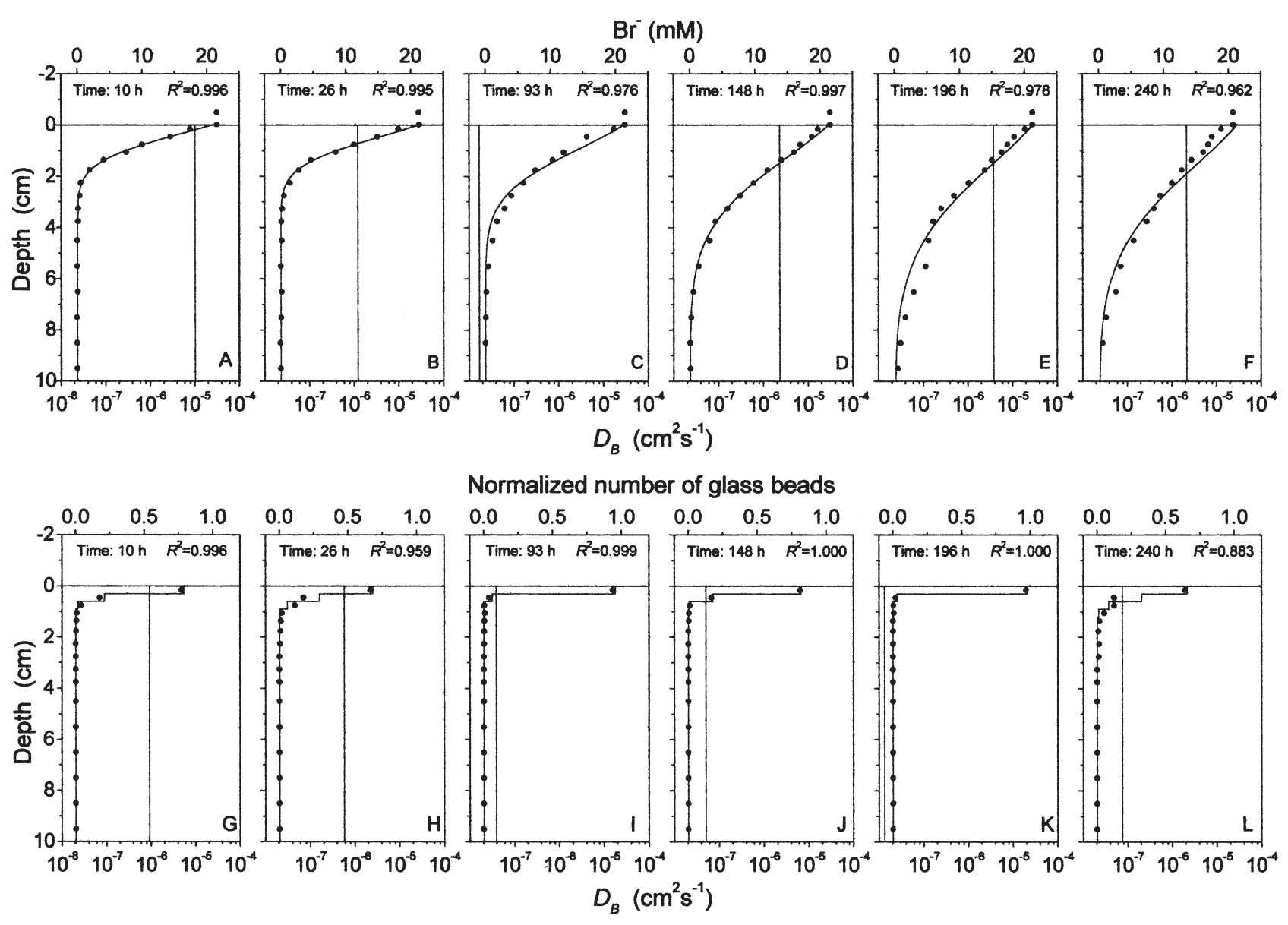

Fig. 2. Measured profiles of $\mathrm{Br}^{-}$and glass beads (dots) for 6 different times (6 different cores) during the tracer experiment, the calculated 'best fitting' profiles (lines), and the estimated $D_{\mathrm{B}}$ values (vertical lines). In all calculations $D_{\mathrm{B}}$ was assumed to be constant with depth. All but 1 estimated $D_{\mathrm{B}}$ value for $\mathrm{Br}^{-}$(at time $93 \mathrm{~h}$ ) were significantly larger than the corresponding values for glass beads

insured a constant $\mathrm{Br}^{-}$concentration above the DBL throughout the tracer experiment. The thickness of the DBL was estimated by interpolation between the measured $\mathrm{O}_{2}$ concentrations to be approximately $0.03 \mathrm{~cm}$. $\mathrm{A} \mathrm{Br}^{-}$concentration of zero was used as a lower boundary condition and also as the initial condition $(t=0)$. A zero flux was specified for the glass beads as the upper boundary condition at the sediment-water interface. As the initial condition $(t=0)$, all glass beads were 'added' to the top control volume $\left(\Delta x_{1}=0.05 \mathrm{~cm}\right)$ right below the sediment surface, while a concentration of zero was specified for all other depths. A fixed concentration of zero was imposed as the lower boundary condition. The numerical solutions were done with a time step $(\Delta t)$ of $60 \mathrm{~s}$ and with a discretization of the sediment column $(10 \mathrm{~cm})$ into 100 control volumes for the $\mathrm{Br}^{-}$calculations and 200 in the calculations for the glass beads. As shown later, this resolution in time and space was found to be more than adequate to give precise numerical solutions.
Following the outlined minimization process, a $D_{\mathrm{B}}$ value was found for each core for both $\mathrm{Br}^{-}$and glass beads. In this first set of calculations, it was assumed that $D_{\mathrm{B}}$ was constant with depth. The results for all 6 cores are shown in Fig. 2. Note the development in time of the $\mathrm{Br}^{-}$profiles, and also how much deeper the $\mathrm{Br}^{-}$profiles penetrate compared to the glass bead profiles. This difference is in part due to molecular diffusion, but also to a significant difference between $D_{\mathrm{B}}$ for $\mathrm{Br}^{-}$and $D_{\mathrm{B}}$ for the glass beads, which on average were estimated to be $3.3 \pm 1.5 \times 10^{-6}(1 \mathrm{SE})$ and $2.8 \pm 1.5 \times$ $10^{-7}(1 \mathrm{SE}) \mathrm{cm}^{2} \mathrm{~s}^{-1}$, respectively. All calculated concentration profiles fit the measured profiles well, with an average $\mathrm{R}^{2}$ value of 0.984 for $\mathrm{Br}^{-}$and 0.973 for the glass beads.

Since some of the $\mathrm{Br}^{-}$profiles had a relatively large penetration depth ( $8 \mathrm{~cm}$ for profile $\mathrm{F})$, we tried to refine the estimates of $D_{\mathrm{B}}$ values for solutes to include any variation with depth. In a new series of calculations, the $10 \mathrm{~cm}$ sediment columns were separated into $2 \mathrm{~cm}$ 
depth intervals, each with 1 value of $D_{\mathrm{B}}$. These $D_{\mathrm{B}}$ values were then found for each core by minimizing Eq. (3) as before. For further details on how this minimization process involving more than 1 variable was performed, see Berg et al. (1998). The average values of $D_{\mathrm{B}}$ for the $2 \mathrm{~cm}$ depth intervals are shown in Fig. 3. Due to the variable penetration depth of the $\mathrm{Br}^{-}$profiles, the number of estimated $D_{\mathrm{B}}$ values for each depth interval decreased with depth, and no $D_{\mathrm{B}}$ values were found for the lowest interval $(8$ to $10 \mathrm{~cm})$. These results suggest that there was a maximum in $D_{\mathrm{B}}$ below the sediment-water interface and that $D_{\mathrm{B}}$ decreased below this maximum. The maximum might be explained by a subsurface maximum abundance of meiofauna, which has been found in other Arctic sediments (Newton \& Rowe 1995, Rysgaard et al. 2000). However, since a comparison of the mean $D_{\mathrm{B}}$ values for the 2 upper depth intervals showed that they were not significantly different ( $p=0.16$, ANOVA), the apparent subsurface maximum possibly reflects uncertainties in the estimated $D_{\mathrm{B}}$ values. For that reason, we concluded that the most representative $D_{\mathrm{B}}$ value for the upper part of the sediment ( 0 to $4 \mathrm{~cm}$ ) was the average value of all 11 individual estimates of $D_{\mathrm{B}}, 4.6 \pm 1.0 \times 10^{-6}(1 \mathrm{SE}) \mathrm{cm}^{2}$ $\mathrm{s}^{-1}$. Since this value is not significantly different from any of the $D_{\mathrm{B}}$ values in the 2 lower depth intervals (ANOVA: 4 to $6 \mathrm{~cm}, \mathrm{p}=0.50 ; 6$ to $8 \mathrm{~cm}, \mathrm{p}=0.17$ ), the data show no strong evidence of a decrease in $D_{\mathrm{B}}$ with depth.

\section{$D_{\mathrm{B}}$ estimated from concentration profiles and fluxes of $\mathrm{O}_{2}$}

The measured mean $\mathrm{O}_{2}$ profile penetrated approximately $1.5 \mathrm{~cm}$ into the sediment (Fig. 4A). In the interpretations of the 6 individual $\mathrm{O}_{2}$ profiles $D_{\mathrm{s}}$ was expressed as $D_{\mathrm{s}}=D /[1+3(1-\varphi)]$ (Iversen \& Jørgensen 1993) using a diffusivity of $\mathrm{O}_{2}$ in water of $11.7 \times 10^{-6}$ $\mathrm{cm}^{2} \mathrm{~s}^{-1}$ at $0^{\circ} \mathrm{C}$ (Broecker \& Peng 1974) and porosities calculated from the fit shown in Fig. 1A. The calculated mean concentration profile (Fig. 4A) provided an excellent fit to the measured mean profile $\left(R^{2}=0.998\right)$. The average flux across the sediment-water interface was calculated to be $4.1 \pm 0.5$ (1 SE) mmol m${ }^{-2} \mathrm{~d}^{-1}$ (Fig. 4B) in the interpretations that only accounted for molecular diffusion. An average flux that was $60 \%$ larger $\left(6.5 \pm 1.0[1 \mathrm{SE}] \mathrm{mmol} \mathrm{m}^{-2} \mathrm{~d}^{-1}\right)$ was found in the $6 \mathrm{O}_{2}$ flux measurements in cores (Fig. 4B). With a value of $\varphi$ of 0.84 in the top of the sediment (Fig. 1A) and a diffusivity of $\mathrm{O}_{2}$ in water of $11.7 \times 10^{-6} \mathrm{~cm}^{2} \mathrm{~s}^{-1}$ (see above), $D_{\mathrm{s}}$ was calculated to be $7.9 \times 10^{-6} \mathrm{~cm}^{2} \mathrm{~s}^{-1}$ (Iversen \& Jørgensen 1993). Based on this value and the 2 fluxes, a $D_{\mathrm{B}}$ value of $4.6 \times 10^{-6} \mathrm{~cm}^{2} \mathrm{~s}^{-1}$ was calculated from Eq. (5). This value is in agreement with the
$D_{\mathrm{B}}$ value that was found from the $\mathrm{Br}^{-}$profiles for the top of the sediment ( 0 to $4 \mathrm{~cm}$ ). In a new series of profile interpretations where bioturbation was included, it was verified that a $D_{\mathrm{B}}$ of $4.6 \times 10^{-6} \mathrm{~cm}^{2} \mathrm{~s}^{-1}$ gave a mean

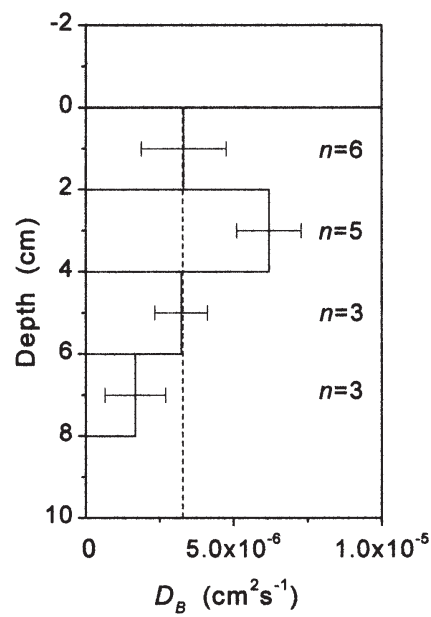

Fig. 3. Mean values of $D_{\mathrm{B}}$ estimated from the $\mathrm{Br}^{-}$profiles where $D_{\mathrm{B}}$ was allowed to vary with depth (error bars represent $\pm 1 \mathrm{SE}$ ). The dashed line represents the average of the $D_{\mathrm{B}}$ values for $\mathrm{Br}^{-}$shown in Fig. 2

$\mathrm{O}_{2}(\mu \mathrm{M})$

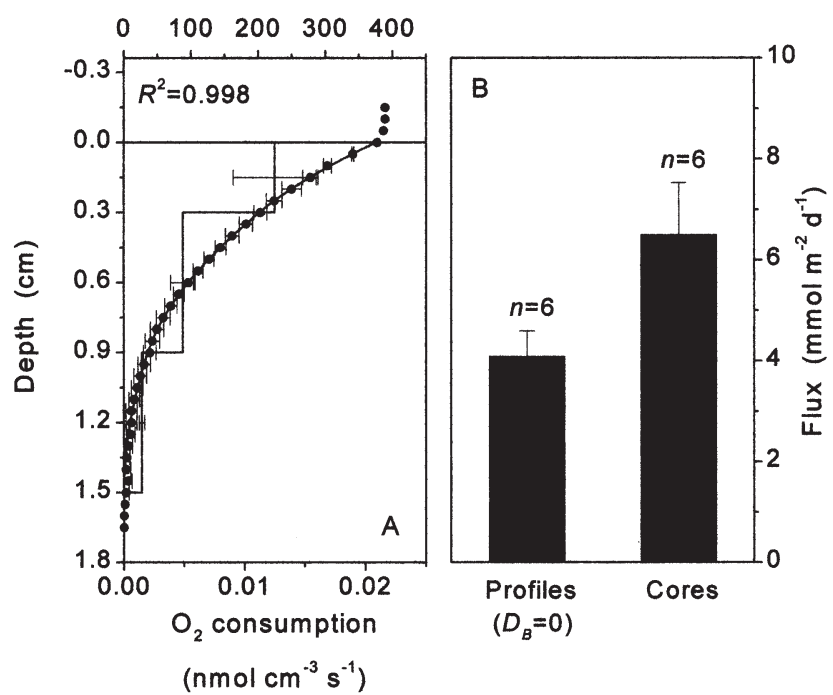

Fig. 4. (A) Average of measured $\mathrm{O}_{2}$ concentration profiles (dots) and the 'best fitting' profile (lines) calculated using the profile interpretation procedure of Berg et al. (1998) (error bars represent $\pm 1 \mathrm{SE}, \mathrm{n}=6$ ). (B) In 1 series of profile interpretations, bioturbation was neglected $\left(D_{\mathrm{B}}=0\right)$, which gave a flux over the sediment-water interface significantly smaller than the flux measured in cores (error bars represent $1 \mathrm{SE}$ ). This difference was used to estimate a value of $D_{\mathrm{B}}$. The mean $\mathrm{O}_{2}$ consumption profile (A) was calculated in a new series of profile interpretations using this value of $D_{\mathrm{B}}$ (error bars represent $\pm 1 \mathrm{SE}, \mathrm{n}=6$ ) 
flux of $6.5 \mathrm{mmol} \mathrm{m}^{-2} \mathrm{~d}^{-1}$. The calculated mean $\mathrm{O}_{2}$ consumption rates from these interpretations are shown in Fig. 4A. The highest consumption rate was found right below the sediment-water interface, and was probably caused by a recent input of fresh organic matter from a phytoplankton bloom.

\section{$D_{\mathrm{B}}$ estimated from from ${ }^{210} \mathrm{~Pb}$ profiles}

Despite some scattered variation in the 2 profiles of unsupported ${ }^{210} \mathrm{~Pb}$ (Fig. 5, Rysgaard et al. 1996, 1998), they both show clearly a linear decrease with depth in the upper part of the sediment followed by a transition zone where the decline becomes significantly steeper. An initial visual interpretation of this characteristic shape of the profiles suggests a near-constant $D_{\mathrm{B}}$ in the upper part of the sediment. This interpretation is based on the analytical solution to Eq. (6) given by an exponential decaying function that assumes that $D_{\mathrm{B}}$ and $\varphi$ are constant with depth and will appear as a straight line in Fig. 5 due to the logarithmic $x$-axis. Furthermore, the steeper decline at the bottom of both ${ }^{210} \mathrm{~Pb}$ profiles relative to the upper part of the sediment reflects a significant decrease in $D_{\mathrm{B}}$, and it is possible that the profiles at this depth primarily are the result of burial effects rather than of bioturbation. This much steeper decline can be interpreted as representing an upper limit for the influence of burial effects on the ${ }^{210} \mathrm{~Pb}$ profiles. Such an interpretation also indicates that bioturbation was the dominant transport in the upper part of the sediment and that the exclusion of burial effects in Eq. (6) is an appropri-

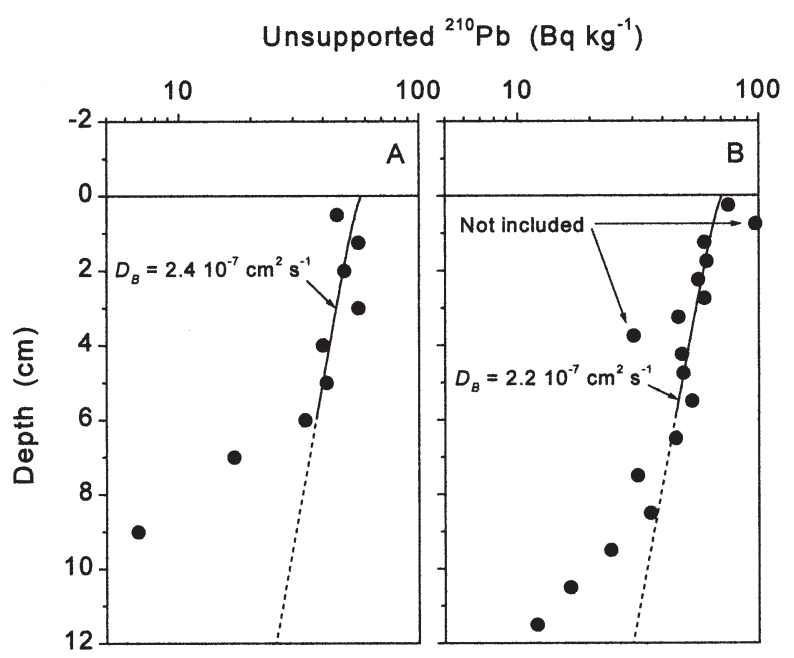

Fig. 5. Estimates of $D_{\mathrm{B}}$ from profiles of unsupported ${ }^{210} \mathrm{~Pb}$ (dots). The 'best fitting' profiles (lines) were calculated from measurements in the top $6 \mathrm{~cm}$ of the sediment and assuming that all particle transport was caused by bioturbation ate assumption when applied to the surficial sediment layers.

In the estimates of $D_{\mathrm{B}}$ from the ${ }^{210} \mathrm{~Pb}$ profiles, as average values for the upper part of the sediment, only the measurements in the top $6 \mathrm{~cm}$ were taken into account. Furthermore, 2 measured data points for 1 of the profiles were considered to be outliers and were excluded from the estimates (Fig. 5B). The depth-dependent values of $\varphi$ required in the numerical solutions of Eq. (6) were determined from the porosity fit (Fig. 1A). The numerical solution was done with a discretization of the sediment column into 200 control volumes which had an extent of $0.12 \mathrm{~cm}$ in the top $12 \mathrm{~cm}$, and at larger depths gradually increased until a total depth of $1 \mathrm{~m}$ below the sediment surface was reached. This relatively large depth was included in the calculations to ensure that the lower boundary condition, a radioactivity of zero, was correctly imposed. Since no precise information was available on the upper boundary condition at the sedimentwater interface, this condition was included as a variable in the optimization process. Thus, 2 variables were found by optimization for each profile: the radioactivity of unsupported ${ }^{210} \mathrm{~Pb}$ at the sedimentwater interface used as the upper boundary condition, and $D_{\mathrm{B}}$ for the upper $6 \mathrm{~cm}$ of the sediment. A decay constant for ${ }^{210} \mathrm{~Pb}(\lambda)$ of $0.0315 \mathrm{yr}^{-1}$ was used in these estimates. As shown later, the chosen discretization of the sediment column was found to be more than adequate to give a precise numerical solution. The 2 fits to the measured ${ }^{210} \mathrm{~Pb}$ profiles are shown in Fig. 5 and the 2 corresponding $D_{\mathrm{B}}$ values were estimated to be $2.4 \times 10^{-7}$ and $2.2 \times 10^{-7} \mathrm{~cm}^{2} \mathrm{~s}^{-1}$, respectively. The 2 fits appear as straight lines in Fig. 5 except for the small curvature directly below the sediment surface, which represents the effect of the depth-dependent porosity.

\section{Abundance of meio- and macrofauna}

The abundance of meiofauna including foraminifers was estimated to be $2.3 \times 10^{6}$ ind. $\mathrm{m}^{-2}$. Foraminifers made up $63 \%$ of the meiofauna population, while nematodes accounted for $27 \%$, copepods $5 \%$, and annelids 5\%. Platyhelminths and other crustacea were present in lower numbers. Nematodes dominated the metazoan meiofauna. The foraminifers were agglutinated species, such as Labrospira sp. (probably L. crassimargo), Psammosphaera fusca, Silicosigmoilina groenlandica and Reophax sp. (probably R. scottii). The calcareous species of foraminifers were represented by Hoeglundina elegans, Norion umbilicatulum, Elphidium albiumbilicatum, and Melonis pompilioides. $S$. groenlandica and E. albiumbilicatum, are typically 
found in shallow waters with a relatively high production (J. E. Wollenburg pers. comm.).

The average abundance of macrofauna as reported by Sejr et al. (2000) was $745 \pm 275$ (1 SE) ind. $\mathrm{m}^{-2}$ ( $\mathrm{n}=$ 10). Seventy percent belonged to the group Polychaeta, $10 \%$ to the molluscs, $8 \%$ to the crustaceans, $3 \%$ to the echinoderms, and $9 \%$ to miscellaneous taxa. Polychaetes were dominated by Cirratulus cirratus, Cirratulus sp., Maldane sarsi, Lumbriclymene minor, and Terebellides stroemi, which together constituted $28 \%$ of the total macrofauna. Other abundant species included the bivalves Hiatella arctica and Astarte spp., which were estimated to be $53 \pm 17$ (1 SE) and $11 \pm 4$ (1 SE) ind. $m^{-2}(n=10)$, respectively. From underwater photos, the abundance of brittle stars (mainly Ophiocten sericeum) was estimated to be $98 \pm 11$ (1 SE) ind. $\mathrm{m}^{-2}(\mathrm{n}=10)$ (Sejr et al. 2000). The abundance of all tube-dwelling species potentially capable of irrigating their tubes (mainly M. sarsi, L. minor and T. stroemi) was approximately 260 ind. $\mathrm{m}^{-2}$.

\section{DISCUSSION}

Our initial plan for this study was to include sediment cores in the incubation experiment with $\mathrm{Br}^{-}$and glass beads where all animals were killed. This would allow us to calculate $D_{\mathrm{B}}$ for the 'killed' cores, where we would expect values close to zero as a control of our experimental design and modeling approach. We determined, however, that it was not possible to kill all animals without altering the sediment structure given the methods available at the remote field station at Young Sound. Commonly used methods such as maintaining the sediment cores under anoxic conditions for some time would kill only a fraction of the animal community. For example, nematodes, which were abundant in the sediment, and other groups of meiofauna are tolerant of anoxic conditions (e.g., Fenchel \& Riedl 1970, Bernard \& Fenchel 1996, Moodley et al. 1997, 1998, Vopel et al. 1998, Gustafsson \& Nordberg 1999). Also, moderate heating of the sediment would unlikely kill all animals. The thermal tolerance of marine meiofauna is poorly explored. However, survival of a marine nematode exposed to temperatures of $45^{\circ} \mathrm{C}$ has been reported (Wieser et al. 1974). Furthermore, some individuals in their resting or encysted stages can tolerate very high environmental stress (e.g., Clegg 1997, Pati et al. 1999). Instead of including such killed control cores in our incubation experiment with $\mathrm{Br}^{-}$and glass beads, we estimated $D_{\mathrm{B}}$ for both solutes and solids using 2 additional approaches, a $D_{\mathrm{B}}$ for solutes calculated from the measured concentration profiles and fluxes of $\mathrm{O}_{2}$ and a $D_{\mathrm{B}}$ for solids estimated from the ${ }^{210} \mathrm{~Pb}$ profiles. It should be emphasized that these

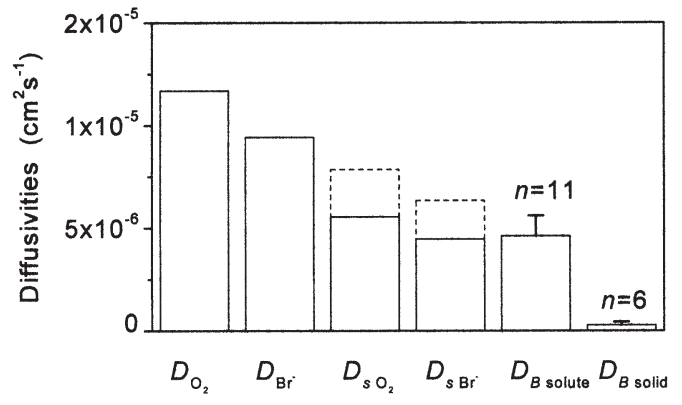

Fig. 6. Diffusivities - the first 2 bars represent the diffusivities (D) of $\mathrm{O}_{2}$ and $\mathrm{Br}^{-}$in water and the next 2 bars represent the sediment diffusivities $\left(D_{\mathrm{s}}\right)$ of $\mathrm{O}_{2}$ and $\mathrm{Br}^{-}$in the top of the sediment (dashed lines, $\varphi=0.84$ ) and in the deeper sediment layers (solid lines, $\varphi=0.63$ ). The last 2 bars represent the estimated biodiffusivities $\left(D_{\mathrm{B}}\right)$ for solutes and for solids (error bars represent $1 \mathrm{SE}$ ). The estimated $D_{\mathrm{B}}$ for solutes is of the same size as the $D_{\mathrm{s}}$ for $\mathrm{O}_{2}$ and $\mathrm{Br}^{-}$and 15 to 20 times larger than $D_{\mathrm{B}}$ for solids

additional estimates of $D_{\mathrm{B}}$ were independent of the $D_{\mathrm{B}}$ values derived form the incubations with $\mathrm{Br}^{-}$and glass beads.

Our estimates of $D_{\mathrm{B}}$ determined from the profiles of $\mathrm{Br}^{-}$and glass beads resulted in 2 significantly different values $\left(\mathrm{p}=0.007\right.$, ANOVA) of $4.6 \pm 1.0 \times 10^{-6}(1 \mathrm{SE})$ and $2.8 \pm 1.5 \times 10^{-7}(1 \mathrm{SE}) \mathrm{cm}^{2} \mathrm{~s}^{-1}$, respectively (Fig. 6) The other estimate for solutes based on the measured concentration profiles and fluxes of $\mathrm{O}_{2}$ gave the same $D_{\mathrm{B}}$ value of $4.6 \times 10^{-6} \mathrm{~cm}^{2} \mathrm{~s}^{-1}$. Finally, the estimates for solids from the two ${ }^{210} \mathrm{~Pb}$ profiles gave $D_{\mathrm{B}}$ values of $2.4 \times 10^{-7}$ and $2.2 \times 10^{-7} \mathrm{~cm}^{2} \mathrm{~s}^{-1}$. The 2 values are, in a statistical sense, equal to the estimate from the glass bead profiles. It should also be emphasized that the small difference between these 2 values does not reflect the level of uncertainty in the interpretations of the ${ }^{210} \mathrm{~Pb}$ profiles, which is considered to be significantly larger.

To our knowledge, such a difference in $D_{\mathrm{B}}$ values for solutes and solids for the same sediment has not been reported previously. We have verified our results by carefully evaluating different aspects and assumptions in our methodology.

\section{Artifacts in the slicing process}

The sediment cores were sliced in an upright position and the slicing was started at the sediment-water interface and then continued down through the sediment. In this process the sediment was pushed upward through the Plexiglas tubes by a piston controlled by a screw $\left(1 \mathrm{~mm} \mathrm{turn}^{-1}\right)$. We have considered 2 possible artifacts associated with the slicing process. Firstly, if there was leakage between the piston and the tube it 
could allow the pore water to drain down through the sediment, making the $\mathrm{Br}^{-}$profiles appear to extend deeper into the sediment than their true position. The result would be an overestimation of $D_{\mathrm{B}}$ for solutes. However, the sediment on our site was very compact and consisted primarily of clay (Fig. 1B), which would prevent such drainage. We observed that even when the bottom of the Plexiglas tube was not closed by the piston, or a rubber stopper, no drainage occurred. Secondly, if sediment was mixed accidentally during the slicing, perhaps caused by a small stone or shell, the profiles of both $\mathrm{Br}^{-}$and glass beads also would appear to extend deeper into the sediment than their real position. Such an artifact would obviously have led to an overestimation of the $D_{\mathrm{B}}$ values for both solutes and solids. That all $\mathrm{Br}^{-}$profiles were relatively smooth and, more importantly, that all the glass bead profiles (Fig. 2G-L) had a small penetration depth indicate that such mixing did not occur. However, our strongest argument against such an artifact in the slicing process is that similar $D_{\mathrm{B}}$ values were estimated independently for both solutes and solids. For these reasons we believe that our measured concentrations of both $\mathrm{Br}^{-}$ and glass beads represent their true values at the particular depths and times when the cores were sliced.

\section{Test of the numerical solution}

The numerical solution of Eqs (1), (2) \& (6) was produced specifically to be used in this study. Since a correct working and precise numerical solution obviously is required for obtaining reliable estimates of $D_{\mathrm{B}}$, we have verified the solution in several tests. In the first test, we compared the numerical solution against an analytical solution describing a transient concentration profile for a solute or solid that is transported down into a sediment by diffusion, or a diffusive-like transport, driven by an elevated and constant concentration at the sediment-water interface. This analytical solution can be found in the large selection of analytical solutions for diagenetic problems published by Boudreau (1997). Since the analytical solution demands a constant porosity with depth, we used a value of 0.63 , equivalent to the fitted porosity at larger depths (Fig. 1A), and we compared the 2 solutions at the time when the first core was sliced $(10 \mathrm{~h})$. The maximum deviation between the $\mathrm{Br}^{-}$profiles calculated by the numerical and the analytical solutions was less that $0.05 \%$ of the concentration specified at the sedimentwater interface $(21.3 \mathrm{mM})$. A similar good agreement was found for the glass beads. The requirement of a constant porosity with depth in the analytical solution does not fit well with our measured porosities, which show a clear depth dependency (Fig. 1A). In a second test we showed that this depth variation also was well represented in our numerical solution with the spatial resolution ( $\mathrm{N}$, the number of control volumes) we used. With a resolution that was refined by a factor of 2 in both space (to $\mathrm{N}=200$ for $\mathrm{Br}^{-}$profiles and $\mathrm{N}=400$ for glass bead profiles) and time (to $\Delta t=30 \mathrm{~s}$ ), we recalculated the same $2 D_{\mathrm{B}}$ values within $0.4 \%$ for the core that was sliced at time $10 \mathrm{~h}$. A similar result was obtained in an equivalent test of the discretization used in the numerical solution of Eq. (6). In addition to serving as a control for our numerical solution, these tests illustrate the high precision with which the 3 mass conservation equations (Eqs 1, 2 \& 6) were solved.

\section{Uncertainties in the measured porosity and sediment diffusivity}

The average measured porosity in the top $1 \mathrm{~cm}$ of the sediment (Fig. 1A) diverged from, and had a larger standard error than, the porosities deeper in the sediment. The measured decrease in the porosity with depth is commonly found in marine sediments, and the larger standard error in the top $1 \mathrm{~cm}$ probably reflected natural variation, as well as difficulties in measuring porosities near the sediment surface. Since the porosity was a variable in Eqs (1), (2) \& (6) and also was a parameter in the expression used for the sediment diffusivity $\left(D_{\mathrm{s}}=D /[1+3(1-\varphi)]\right.$, Iversen \& Jørgensen 1993), we examined how sensitive the estimates of $D_{\mathrm{B}}$ were to uncertainties in the porosity. All estimates of $D_{\mathrm{B}}$ shown in Fig. 2 were recalculated with porosity 'fits' that were changed from the original fit $\pm 2.5 \times$ the upper standard error near the sediment-water interface (dotted lines in Fig. 1A). With this variation, the mean $D_{\mathrm{B}}$ value estimated from the $\mathrm{Br}^{-}$profiles changed $27 \%$ from its original value. The equivalent change for the mean $D_{\mathrm{B}}$ value for the glass bead profiles was only $10 \%$. Even with such a variation in porosity (Fig. 1A), which probably is larger than the natural variation in the sediment, the calculated changes in $D_{\mathrm{B}}$ values were insignificant compared to the large difference between the estimated $D_{\mathrm{B}}$ values from the $\mathrm{Br}^{-}$and glass bead profiles. In a similar analysis, it was determined that the same variation in the porosity affected the $D_{\mathrm{B}}$ values estimated from the two ${ }^{210} \mathrm{~Pb}$ profiles by less than $10 \%$.

Another key parameter in the estimated $D_{\mathrm{B}}$ values was the sediment diffusivity. Uncertainties in $D_{\mathrm{s}}$ can originate from the porosity measurements, or the diffusivity of $\mathrm{Br}^{-}$in water $(D)$, and perhaps more importantly, by the approximation of $D_{\mathrm{s}}$ itself $\left(D_{\mathrm{s}}=D /[1+3(1-\varphi)]\right.$, Iversen \& Jørgensen 1993). All estimates were based on a diffusivity for $\mathrm{Br}^{-}$in water of $9.43 \times 10^{-6} \mathrm{~cm}^{2} \mathrm{~s}^{-1}$, which was calculated from the temperature correlation given by Boudreau (1997) $\left(-1^{\circ} \mathrm{C}\right)$. If a direct linear regression 
to the measurements of Li \& Gregory (1974) (at 0, 18, and $25^{\circ} \mathrm{C}, \mathrm{R}^{2}=1.000$ ) were used instead, the calculated diffusivity would have been $10.03 \times 10^{-6} \mathrm{~cm}^{2} \mathrm{~s}^{-1}$, which is $6 \%$ larger than the value we used originally. With the approximation of Iversen \& Jørgensen (1993), $D_{\mathrm{s}}$ was calculated to be $6.37 \times 10^{-6}$ and $4.47 \times 10^{-6} \mathrm{~cm}^{2} \mathrm{~s}^{-1}$ for the very top of the sediment $(\varphi=0.84)$ and for the deeper sediment layers $(\varphi=0.63)$, respectively. Boudreau (1997) has recently suggested an alternative correlation for $D_{\mathrm{s}}$ as a general representation for finegrained sediments, $D_{\mathrm{s}}=D /\left[1-\ln \left(\varphi^{2}\right)\right]$, which gives values of $D_{\mathrm{s}}$ of $6.99 \times 10^{-6}$ and $4.90 \times 10^{-6} \mathrm{~cm}^{2} \mathrm{~s}^{-1}$ for the same 2 porosities. These values are both $10 \%$ larger than the ones that were used originally. A sensitivity analysis similar to the one for the porosity showed that a $10 \%$ variation in $D_{\mathrm{s}}$ gave a $16 \%$ variation in the estimated mean $D_{\mathrm{B}}$ value from the $\mathrm{Br}^{-}$profiles. It should be noted that $D_{\mathrm{s}}$ does not occur in the estimates of $D_{\mathrm{B}}$ from the glass bead and ${ }^{210} \mathrm{~Pb}$ profiles. The 2 sensitivity analyses for the porosity and $D_{\mathrm{s}}$ show that any uncertainties in these 2 variables cannot lead to any significant changes in the estimated $D_{\mathrm{B}}$ values.

\section{Bioturbation versus irrigation}

Irrigation (i.e., the exchange of pore water and bottom water caused by pumping activity of tubedwelling animals) can enhance the transport of solutes in sediments significantly (Aller 1983, Pelegri et al. 1994, Wang \& Van Cappellen 1996). By including all tube-dwelling species potentially capable of irrigating their tubes, the density of such animals was estimated to be 260 ind. $\mathrm{m}^{-2}$. We have evaluated whether or not irrigation could explain some of the large difference between the estimated $D_{\mathrm{B}}$ values for the dissolved and solid tracers.

Irrigation is a multi-dimensional transport phenomenon (Aller 1980). However, it is possible to include irrigation in 1-dimensional formulations such as Eq. (1) by adding the non-local source-sink function $\varphi \alpha\left(C_{0}-C\right)$ suggested by Boudreau $(1984,1997)$ to the right-hand side of the equation, where $\alpha$ is the irrigation coefficient and $C_{0}$ is the bottom water concentration. This function, or term, does not express any diffusive or diffusive-like transport such as molecular diffusion or bioturbation. Profiles that develop under a strong influence of irrigation have a different shape than profiles established due to diffusive transport (Matisoff \& Wang 1998), and there is often a local maximum at a certain depth (Rasmussen et al. 1998, Forster et al. 1999). The shape and smoothness of the $\mathrm{Br}^{-}$profiles indicate that diffusion or a diffusive-like transport process was the dominant one in the sediment. The fact that all the individual $\mathrm{O}_{2}$ profiles also were very smooth (no abrupt changes in the error bars, Fig. 4A) supports this argument. It should be noted that the $\mathrm{O}_{2}$ profiles were measured on a much finer scale than the $\mathrm{Br}^{-}$profiles, and while the $\mathrm{Br}^{-}$numbers represent average values for each slice of sediment, the $\mathrm{O}_{2}$ values are true point measurements. The smoothness of the $\mathrm{O}_{2}$ profiles indicates not only that they were established by a diffusive-like transport, but also that the contribution from bioturbation was primarily a result of the activity of smaller animals (meiofauna).

We did not observe any tube-dwelling animals or worm holes when the cores were examined prior to the tracer experiment and the $\mathrm{O}_{2}$ profile-flux measurements, nor was there any evidence of larger animals found when the cores from the tracer experiment were sliced. However, given the abundance of 260 worms $\mathrm{m}^{-2}$, there should have been 1 individual in every second core (area $\sim 22 \mathrm{~cm}^{2}$ ). If we overlooked a worm hole in one of the cores, it was small $(<1 \mathrm{~mm})$ and probably located in one of the cores used for $\mathrm{O}_{2}$ flux measurements, since all other cores were subject to a closer inspection, either during the slicing process or prior to the $\mathrm{O}_{2}$ profile measurements. Therefore, it was estimated how much an active worm that keeps its tube fully ventilated with $\mathrm{O}_{2}$-rich water from the water column could enhance $\mathrm{O}_{2}$ uptake by the sediment. For this estimate, we used an analytical solution (see Appendix 1) for the steady-state, 1-dimensional radial transport of $\mathrm{O}_{2}$ through a tube wall. The necessary input parameters were determined as follows: Based on the measured $\mathrm{O}_{2}$ fluxes of $6.5 \mathrm{mmol} \mathrm{m}^{-2} \mathrm{~d}^{-1}$ (Fig. 4B) and a penetration depth of $1.5 \mathrm{~cm}$ (Fig. $4 \mathrm{~A}$ ), an average value of the $\mathrm{O}_{2}$ consumption rate $(-R)$ of $5.0 \mathrm{pmol} \mathrm{cm} \mathrm{cm}^{-3}$ $\mathrm{s}^{-1}$ was assumed. A value of $D_{\mathrm{B}}$ of $4.6 \times 10^{-6} \mathrm{~cm}^{2} \mathrm{~s}^{-1}$ was used as it was found from both the $\mathrm{Br}^{-}$profiles and the $\mathrm{O}_{2}$ profile-flux comparisons. Based on a average value of $\varphi$ of 0.7 , and a diffusivity of $\mathrm{O}_{2}$ in water of $11.7 \times 10^{-6}$ $\mathrm{cm}^{2} \mathrm{~s}^{-1}$ (see above), $D_{\mathrm{s}}$ was calculated to be $6.2 \times 10^{-6}$ $\mathrm{cm}^{2} \mathrm{~s}^{-1}$ according to Iversen \& Jørgensen (1993). The measured water column $\mathrm{O}_{2}$ concentration $\left(C_{0}\right)$ of $389 \mu \mathrm{M}$ was used, and the tube depth $(L)$ and tube radius $\left(r_{1}\right)$ were assumed to be 2 and $0.05 \mathrm{~cm}$, respectively. With these values, the horizontal penetration depth $\left(r_{2}\right)$ where all $\mathrm{O}_{2}$ is consumed was calculated to be $0.74 \mathrm{~cm}$ (Eq. A5), and the total $\mathrm{O}_{2}$ uptake through the tube wall was calculated to be $1.5 \mu \mathrm{mol} \mathrm{\textrm {d } ^ { - 1 }}$ (Eq. A7). This is equal to $11 \%$ of the measured average $\mathrm{O}_{2}$ uptake per core of $14 \mu_{\mathrm{mol} \mathrm{d}}{ }^{-1}$ (Fig. 4B). Recall that only 1 individual was expected in every second core if all potential irrigating animals were accounted for, and in addition, that no larger worms were observed when the cores were examined. From this perspective we evaluate that irrigation from 1 or perhaps 2 smaller worms that might have been overlooked could not significantly influence the estimated $D_{\mathrm{B}}$ value for solutes. 


\section{Accuracy of the estimated $D_{\mathrm{B}}$ values}

The estimated $D_{\mathrm{B}}$ value for solutes of $4.6 \pm 1.0 \times$ $10^{-6}$ (1 SE) $\mathrm{cm}^{2} \mathrm{~s}^{-1}$ was found using 2 independent methods and was validated by sensitivity analyses and evaluations of possible artifacts associated with our methods. In addition, this $D_{\mathrm{B}}$ value agrees well with the enhanced pore water transport, a factor of approximately 2, caused by the movement of meiofauna found by Aller \& Aller (1992). Although we are confident that the estimated $D_{\mathrm{B}}$ value for solids of $2.8 \pm 1.5 \times 10^{-7}(1 \mathrm{SE}) \mathrm{cm}^{2} \mathrm{~s}^{-1}$ estimated from the glass bead profiles, or the mean value of $2.3 \times 10^{-7}$ $\mathrm{cm}^{2} \mathrm{~s}^{-1}$ estimated from the two ${ }^{210} \mathrm{~Pb}$ profiles, is significantly smaller than the $D_{\mathrm{B}}$ value for solutes, we note that it is considerably more uncertain than our estimates for solutes. Firstly, the mean value of $D_{\mathrm{B}}$ estimated from the glass bead profiles is only significantly different from zero at a significance level of 0.13 ( $t$-test). Secondly, all 6 individual values of $D_{\mathrm{B}}$ (Fig. 2G to L) are based on a resolution, defined here as the number of data points within the penetration depth of the profile, which is much lower for the glass beads than for $\mathrm{Br}^{-}$. This obviously makes the estimates of $D_{\mathrm{B}}$ from the glass bead profiles more uncertain. The two ${ }^{210} \mathrm{~Pb}$ profiles (Fig. 5) contained some scattered variation which adds to the uncertainty in their interpretation. However, a comparison with other studies where $D_{\mathrm{B}}$ also was estimated from solid tracers supports our findings. Using an average burial velocity $(w)$ on the study site of $0.23 \mathrm{~cm} \mathrm{yr}^{-1}$ (Rysgaard et al. 1998) and the regression for $D_{\mathrm{B}}$ versus $w$ derived by Boudreau $(1994,1997)$ gives a $D_{\mathrm{B}}$ value of $1.8 \times 10^{-7} \mathrm{~cm}^{2} \mathrm{~s}^{-1}$. If the regression suggested by Middelburg et al. (1997) for $D_{\mathrm{B}}$ versus water depth $(z)$ is used, a value of $7.8 \times 10^{-7} \mathrm{~cm}^{2} \mathrm{~s}^{-1}$ is obtained ( $z=36 \mathrm{~m}$, Rysgaard et al. 1998). These 2 regressions were derived from numerous studies of the mixing of solids $\left({ }^{210} \mathrm{~Pb}\right)$ in surficial sediment layers. Our estimated $D_{\mathrm{B}}$ values lie in the interval defined by the 2 regression values.

\section{CONCLUSION}

The results of this study show that the transport of solutes by bioturbation was equally as important as molecular diffusion ( $D_{\mathrm{s}} \sim D_{\mathrm{B}}$ for solutes, Fig. 6), and that bioturbation had a significantly greater effect on solutes than on solids. This is reflected in the estimated $D_{\mathrm{B}}$ values; the value for solutes was 15 to 20 times larger that the value for solids. The $D_{\mathrm{B}}$ values for both solutes and solids were estimated using 2 independent methods that statistically gave the same results, which together with a detailed evaluation of the methodologies and assumptions used served as a validation of these estimates.

In one of the methods for estimating $D_{\mathrm{B}}$ for solutes, the ratio between $\mathrm{O}_{2}$ fluxes from direct measurements and fluxes from interpretation of $\mathrm{O}_{2}$ concentration profiles was used. This new approach worked successfully, and compared to more laborious tracer experiments, it proved to be a good alternative for predicting the level of bioturbation for solutes in the surficial sediment layer.

All $\mathrm{O}_{2}$ profiles were measured on a fine scale of $0.05 \mathrm{~cm}$, and each individual profile as well as the point-to-point variation within each profile exhibited a very smooth curvature. This smoothness suggests that the transport of $\mathrm{O}_{2}$ by bioturbation down through the sediment was primarily a result of the activity of meiofauna rather than of larger animals.

The abundance of meiofauna $\left(2.3 \times 10^{6}\right.$ ind. $\left.\mathrm{m}^{-2}\right)$ and composition of taxa are comparable to other findings for subtidal marine muddy sediments (Jensen 1983, Rudnick et al. 1985, Rysgaard et al. 2000). As in most other marine sediments, nematodes dominated the metazoan meiofauna (McIntyre 1969). Based on these key characteristics, we believe that our results are not only limited to this site, but also may apply to many other marine sediments.

It is generally recognized that bioturbation can be described mathematically as a diffusive process. We recommend that this formulation be extended to include 2 different biodiffusivities, one for solutes and one for solids.

\section{Appendix 1}

The steady-state 1-dimensional transport of a solute $C$ along a radius $r$ yields:

$$
\frac{1}{r} \frac{\mathrm{d}}{\mathrm{d} r}\left(r \varphi\left(D_{\mathrm{s}}+D_{\mathrm{B}}\right) \frac{\mathrm{d} C}{\mathrm{~d} r}\right)=-R
$$

where $R$ is the net rate of production (or consumption if $R$ is negative) per unit volume of sediment (Boudreau 1997). Assuming that $R$ and $\varphi\left(D_{\mathrm{s}}+D_{\mathrm{B}}\right)$ are constant with $r$, Eq. (A1) can be solved analytically, which gives:

$$
C=-\frac{R}{4 \varphi\left(D_{\mathrm{s}}+D_{\mathrm{B}}\right)} r^{2}+\mathrm{A} \ln r+\mathrm{B}
$$

where A and B are arbitrary constants. From Eq. (A2), the flux through the tube wall can be derived:

$$
-\left.\varphi\left(D_{\mathrm{s}}+D_{\mathrm{B}}\right) \frac{\mathrm{d} C}{\mathrm{~d} r}\right|_{r_{1}}=\frac{R}{2} r_{1}-\frac{\varphi\left(D_{\mathrm{s}}+D_{\mathrm{B}}\right) \mathrm{A}}{r_{1}}
$$

where $r_{1}$ is the radius of the tube. Using Eq. (A2) and the following 3 boundary conditions, 3 equations for $r_{2}$ and the arbitrary constants A, B can be derived:

$$
\begin{aligned}
& r=r_{1}: C=C_{0}, \quad r=r_{2}: C=0, \text { and } \\
& r=r_{2}: \frac{\mathrm{d} C}{\mathrm{~d} r}=0
\end{aligned}
$$


Appendix 1 (continued)

where $C_{0}$ is the water column $\mathrm{O}_{2}$ concentration pumped down into the tube and $r_{2}$ is the radius at which all $\mathrm{O}_{2}$ is consumed. The equation for $r_{2}$ contains an iteration:

$$
r_{2 n+1}=\sqrt{\frac{r_{2}^{2}-r_{1}^{2}-\frac{4 \varphi\left(D_{\mathrm{s}}+D_{\mathrm{B}}\right) C_{0}}{R}}{2\left(\ln r_{2 n}-\ln r_{1}\right)}}
$$

where the subscripts $n+1$ and $n$ refer to the new and the previous value of $r_{2}$, respectively. The iteration can, for example, be initiated with a value of $r_{2}$ of $2 \times r_{1}$. After $r_{2}$ is found, the arbitrary constants, A and B, can be calculated from:

$$
\begin{aligned}
\mathrm{A} & =\frac{R}{2 \varphi\left(D_{\mathrm{s}}+D_{\mathrm{B}}\right)} r_{2}^{2} \\
\mathrm{~B} & =\mathrm{A}\left(\frac{1}{2}-\ln r_{2}\right)
\end{aligned}
$$

The total $\mathrm{O}_{2}$ uptake due to irrigation $\left(F_{\text {irr }}\right)$ can be estimated using Eq. (A3) for the flux through the tube wall and the symbol $L$ for the depth of the fully irrigated tube as:

$$
\begin{gathered}
F_{\text {irr }}=-\left.\varphi\left(D_{\mathrm{s}}+D_{\mathrm{B}}\right) \frac{\mathrm{d} C}{\mathrm{~d} r}\right|_{r_{1}}\left(2 \pi r_{1} L\right)= \\
{\left[R r_{1}^{2}-2 \varphi\left(D_{\mathrm{s}}+D_{\mathrm{B}}\right) \mathrm{A}\right] \pi L}
\end{gathered}
$$

Near the sediment-water interface the horizontal diffusive transport of $\mathrm{O}_{2}$ through the tube wall and into the sediment is superimposed by a vertical transport over the sediment-water interface. The total transport in this part of the sediment around the top of a tube wall is truly 2dimensional ( $r$ and $x$ ), and by using the 1-dimensional formulation we might overestimate the effect of irrigation. The assumption that the tube is fully ventilated at all times (the steady-state assumption), so that the concentration on the tube wall persistently equals $C_{0}$, will probably also lead to an overestimation. However, the analytical solution is only used in a first-order estimate of the effect of irrigation on $\mathrm{O}_{2}$ uptake by the sediment.
Acknowledgements. We thank K. McGlathery for reading the manuscript and $T$. Cedhagen for determining the foraminifers. This study was supported by grants from the Danish National Science Research Councils contracts no. 9501025 and 9700224 (S.R.).

\section{LITERATURE CITED}

Aller RC (1980) Quantifying solute distributions in the bioturbated zone of marine sediments by defining an average microenvironment. Geochim Cosmochim Acta 44: 1955-1965

Aller RC (1982) The effects of macrobenthos on chemical properties of marine sediment and overlying water. In: McCall PL, Tevesz MJS (eds) Animal-sediment relations. Plenum, New York, p 53-102

Aller RC (1983) The importance of the diffusive permeability of animal burrow linings in determining marine sediment chemistry. J Mar Res 41:299-322

Aller RC, Aller JY (1992) Meiofauna and solute transport in marine muds. Limnol Oceanogr 37:1018-1033

Aller RC, Yingst JY (1985) Effects of the marine deposit-feeders Heteromastus filiformis (Polychaeta), Macoma balthica (Bivalvia) and Tellina texana (Bilvalvia) on averaged sedimentary solute transport, reaction rates, and microbial distributions. J Mar Res 43:615-645

Berg P, Risgaard-Petersen N, Rysgaard S (1998) Interpretation of measured concentration profiles in sediment pore water. Limnol Oceanogr 43:1500-1510

Bernard C, Fenchel T (1996) Some microaerobic ciliates are facultative anaerobes. Eur J Protistol 32:293-297

Berner RA (1980) Early diagenesis. A theoretical approach. Princeton University Press, Princeton, NJ

Boudreau BP (1984) On the equivalence of nonlocal and radial-diffusion models for porewater irrigation. J Mar Res 42:731-735

Boudreau BP (1994) Is burial velocity a master parameter for bioturbation? Geochim Cosmochim Acta 58:1243-1249

Boudreau BP (1997) Diagenetic models and their implementation. Springer-Verlag, Berlin
Broecker WS, Peng TH (1974) Gas exchange rates between air and sea. Tellus 26:21-35

Clegg JS (1997) Embryos of Artemia franciscana survive four years of continuous anoxia: the case for complete metabolic rate depression. J Exp Biol 200:467-475

Dhakar SP, Burdige DJ (1996) A coupled, non-linear, steady state model for early diagenetic processes in pelagic sediments. Am J Sci 296:296-330

Fenchel T, Glud RN (1998) Veil architecture in a sulphideoxidizing bacterium enhances countercurrent flux. Nature 394:367-369.

Fenchel T, Riedl RJ (1970) The sulfide system: a new biotic community underneath the oxidized layer of marine sand bottoms. Mar Biol 7:255-268

Forster S, Graf G, Kitlar J, Powilleit M (1995) Effects of bioturbation in oxic and hypoxic conditions: a microcosm experiment with a North Sea sediment community. Mar Ecol Prog Ser 116:153-161

Forster S, Glud RN, Gunnersen JK, Hüttel M (1999) In situ study of bromide tracer and oxygen flux in coastal sediments. Estuar Coast Shelf Sci 49:813-827

Glud RN, Fenchel T (1999) The importance of ciliates for interstitial solute transport in marine sediments. Mar Ecol Prog Ser 186:87-93

Glud RN, Jensen K, Revsbech NP (1995) Diffusivity in surficial sediments and benthic mats determined by use of a combined $\mathrm{N}_{2} \mathrm{O}-\mathrm{O}_{2}$ microsensor. Geochim Cosmochim Acta 59:231-237

Gustafsson M, Nordberg K (1999) Benthic foraminifera and their response to hydrography, periodic hypoxic conditions and primary production in the Koljo fjord on the Swedish west coast. J Sea Res 41:163-178

Iversen N, Jørgensen BB (1993) Measurements of the diffusion coefficients in marine sediments: influence of porosity. Geochim Cosmochim Acta 57:571-578

Jensen P (1983) Meiofaunal abundance and vertical zonation in a sublittoral soft bottom, with a test of the Haps corer. Mar Biol 74:319-326

Li YH, Gregory S (1974) Diffusion of ions in sea water and in deep-sea sediments. Geochim Cosmochim Acta 38: $703-714$ 
Matisoff G, Wang X (1998) Solute transport in sediments by freshwater infaunal bioirrigators. Limnol Oceanogr 43: 1487-1499

McIntyre AD (1969) Ecology of marine meiobenthos. Biol Rev 44:245-290

Middelburg JJ, Soetaert K, Herman PMJ (1997) Empirical relationships for use in global diagenetic models. DeepSea Res 44:327-344

Moodley L, van der Zwaan GJ, Herman PMJ, Kempers L, van Breugel P (1997) Differential response of benthic meiofauna to anoxia with special reference to Foraminifera (Protista: Sarcodina). Mar Ecol Prog Ser 158:151-163

Moodley L, van der Zwaan GJ, Rutten GMW, Boom RCE, Kempers AJ (1998) Subsurface activity of benthic foraminifera in relation to porewater oxygen content: laboratory experiments. Mar Micropaleontol 34:91-106

Mulsow S, Boudreau BP, Smith JN (1998) Bioturbation and porosity gradients. Limnol Oceanogr 43:1-9

Newton AC, Rowe GT (1995) The abundance of benthic calcareous Foraminifera and other meiofauna at a time series station in the Northeast Water Polynya, Greenland. J Geophys Res 100:4423-4438

Östlund P, Hallenberg RO, Hallstadius L (1989) Porewater mixing by microorganisms, monitored by a radiotracer method. Geomicrobiol J 7:253-264

Pati AC, Belmonte G, Ceccherelli VU, Boero F (1999) The inactive temporary component: An unexplored fraction of meiobenthos. Mar Biol 134:419-427

Pelegri SP, Nielsen LP, Blackburn TH (1994) Denitrification in estuarine sediment stimulated by the irrigation activity of the amphipod Corophium volutator. Mar Ecol Prog Ser 105:285-290

Rasmussen AD, Banta GT, Andersen O (1998) Effects of bioturbation by the lugworm Arenicola marina on cadmium uptake and distribution in sandy sediments. Mar Ecol Prog Ser 164:179-188

Reeburgh WS (1967) An improved interstitial water sampler. Limnol Oceanogr 12:163-165

Revsbech NP (1989) An oxygen microelectrode with a guard cathode. Limnol Oceanogr 34:474-478

Editorial responsibility: Frede Thingstad, Bergen, Norway
Rudnick DT, Elmgren R, Frithsen JB (1985) Meiofaunal prominence and benthic seasonality in a coastal marine ecosystem. Oecologia 67:157-168

Rysgaard S, Finster K, Dahlgaard H. (1996) Primary production, nutrient dynamics and mineralization in a northeastern Greenland fjord during the sommer thaw. Polar Biol 16:497-506

Rysgaard S, Thamdrup B, Risgaard-Petersen N, Fossing H, Berg P, Christensen PB, Dalsgaard T (1998) Seasonal carbon and nitrogen mineralization in a high-Arctic coastal marine sediment, Young Sound, Northeast Greenland. Mar Ecol Prog Ser 175:261-276

Rysgaard S, Christensen PB, Sørensen MV, Funch P, Berg P (2000) Marine meiofauna, carbon and nitrogen mineralization in sandy and soft sediments of Disko Bay, West Greenland. Aquat Microb Ecol 21:59-71

Sejr MK, Jensen KT, Rysgaard S. (2000) Macrozoobenthos in a Northeast Greenland Fjord: structure and diversity. Polar Biol 23:792-801

Soetaert K, Herman PMJ, Middelburg JJ (1996) A model of early diagenetic processes from the shelf to abyssal depths. Geochim Cosmochim Acta 60:1019-1040

Van Cappellen P, Wang Y (1996) Cycling of iron and manganese in surface sediments: A general theory for the coupled transport and reaction of carbon, oxygen, nitrogen, sulfur, iron, and manganese. Am J Sci 296:197-243

Vopel K, Dehmlow J, Johansson M, Arlt G (1998) Effects of anoxia and sulphide on populations of Cletocamptus confluens (Copepoda, Harpacticoida). Mar Ecol Prog Ser 175: 121-128

Wang Y, van Cappellen P (1996) A multicomponent reactive transport model of early diagenesis: application to redox cycling in coastal marine sediments. Geochim Cosmochim Acta 60:2993-3014

Wieser W, Ott J, Schiemer F, Gnaiger E (1974) An ecophysiological study of some meiofauna species inhabiting a sandy beach at Bermuda. Mar Biol 26:235-248

Wollenburg JE, Mackensen A (1998) On the vertical distribution of living (rose bengal stained) benthic foraminifers in the Arctic Ocean. J Foraminif Res 28:268-285

Submitted: December 15, 2000; Accepted: August 9, 2001 Proofs received from author(s): October 18, 2001 